\title{
Acta Clinica Belgica
}

International Journal of Clinical and Laboratory Medicine

ISSN: 1784-3286 (Print) 2295-3337 (Online) Journal homepage: http://www.tandfonline.com/loi/yacb20

\section{Rituximab in systemic autoimmune rheumatic diseases: indications and practical use}

\section{Nathalie Berghen, Jean-Baptiste Vulsteke, Rene Westhovens, Jan Lenaerts \& Ellen De Langhe}

To cite this article: Nathalie Berghen, Jean-Baptiste Vulsteke, Rene Westhovens, Jan Lenaerts \& Ellen De Langhe (2018): Rituximab in systemic autoimmune rheumatic diseases: indications and practical use, Acta Clinica Belgica, DOI: 10.1080/17843286.2018.1521904

To link to this article: https://doi.org/10.1080/17843286.2018.1521904

View supplementary material $\widetilde{ }$

曲 Published online: 26 Sep 2018.

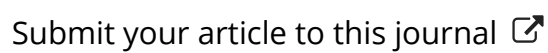

View Crossmark data $\asymp$ 


\title{
Rituximab in systemic autoimmune rheumatic diseases: indications and practical use
}

\author{
Nathalie Berghen $\mathbb{D}^{\mathrm{a}, \mathrm{b} *}$, Jean-Baptiste Vulsteke $\mathbb{D}^{\mathrm{a}}{ }^{\mathrm{*}}$, Rene Westhovens ${ }^{\mathrm{a}, \mathrm{b}}$, Jan Lenaerts ${ }^{\mathrm{a}}$ and Ellen De Langhe ${ }^{\mathrm{a}, \mathrm{b}}$ \\ aDepartment of Rheumatology, University Hospitals Leuven, Leuven, Belgium; bepartment of Development and Regeneration, Skeletal \\ Biology and Engineering Research Center, KU Leuven, Belgium
}

\begin{abstract}
Objectives: To review the therapeutic option of Rituximab, a chimeric anti-CD20 antibody, in systemic autoimmune rheumatic diseases (SARDs) such as systemic lupus erythematosus, systemic sclerosis, primary Sjögren syndrome and idiopathic inflammatory myopathy.

Methods: A non-systematic review was conducted.

Results: The specific role and indication of rituximab in SARDs has been the subject of multiple trials in recent years. Evidence supports the use of rituximab in moderate-to-severe refractory systemic lupus erythematosus, diffuse skin involvement in systemic sclerosis and systemic involvement in primary Sjögren syndrome. Several guidelines have adopted these indications. In addition, there is a consensus about the use of rituximab in refractory myositis. The role of rituximab in interstitial lung disease associated with these SARDs needs to be further explored. Conclusion: Rituximab is a treatment option in several SARDs. Upcoming trials, use in daily practice and the safety profile are elaborated on.
\end{abstract}

\section{KEYWORDS}

Rituximab; systemic autoimmune rheumatic disease; systemic lupus erythematosus; systemic sclerosis; primary Sjögren syndrome; inflammatory myopathy; myositis

\section{Introduction}

Rituximab is a chimeric monoclonal anti-CD20 antibody. CD20 is an antigen expressed in all stages of B-cell development except for the earliest (pro-B-cells) and latest stages (plasma blasts and plasma cells). It is presumed to play a central role in the generation of B-cell responses against $\mathrm{T}$-cell independent antigens [1]. Rituximab induces B-cell depletion through complement-mediated cytotoxicity, antibody-dependent cellular cytotoxicity (ADCC) and direct signaling [2]. It was first approved for the treatment of indolent non-Hodgkin lymphoma (NHL) in 1994. It has been endorsed since for other hematological malignancies as chronic lymphatic leukemia (CLL) and more aggressive NHLs such as diffuse large B-cell lymphoma [3]. In this context, rituximab is administered in doses of $375 \mathrm{mg} / \mathrm{m}^{2}$ body surface area (the 'lymphoma dose') using varying administration intervals. Furthermore, it has later been approved for remission induction and maintenance therapy of ANCA-associated vasculitis (AAV) $[4,5]$ and for treatment of rheumatoid arthritis (RA), the most prevalent of systemic autoimmune rheumatic diseases (SARDs), after failing TNF blockers [6]. Considering the widely accepted indications for the use of rituximab in the treatment of RA, we do not cover the details on the use of rituximab in RA in this manuscript.

Over the last few years, rituximab has been used off-label in transplant rejection and immune-mediated diseases such as multiple sclerosis, autoimmune hemolytic anemia, immune thrombocytopenic purpura, and SARDs other than RA. These SARDs include, amongst others, systemic lupus erythematosus (SLE), systemic sclerosis (SSc), primary Sjögren syndrome (pSS) and idiopathic inflammatory myopathy (IIM). The complex pathogenesis of most SARDs is incompletely understood but an essential role for B cells in the autoimmune response in these diseases seems clear, providing a rationale for the use of rituximab, a B-cell depleting agent. In Belgium treatment with rituximab is partially and conditionally reimbursed in serious immune-mediated diseases since 1 January 2018 if this treatment is based on available scientific evidence supporting the efficacy and safety in the specific indication [7]. The reimbursement request needs to be done by the treating physician electronically via eHealth and one can apply for Mabthera ${ }^{\circledR}$ as well as for the biosimilar Truxima ${ }^{\circledast}$. This new regulation paralleled the price reductions when the biosimilar came to the market.

In this review, we will discuss the current evidence, guidelines, and upcoming trials for rituximab in the abovementioned SARDs. In addition, the practical use and safety profile of rituximab will be discussed. The current overview can be used as a guidance for clinicians caring for patients with these diseases in Belgium, but might also be useful for physicians in other countries.

CONTACT Ellen De Langhe Ellen.Delanghe@uzleuven.be E Department of Rheumatology, University Hospitals Leuven, Herestraat 49 , B-3000 Leuven

*Both authors contributed equally

(1) Supplemental data can be accessed here

(c) 2018 Acta Clinica Belgica 


\section{Methodology}

We conducted a non-systematic review. Briefly, a search was carried out in PubMed in January 2018 using the following search terms: rituximab AND (SLE), rituximab AND (SSc OR scleroderma), rituximab AND (pSS), rituximab AND (IIM OR myositis). All titles and abstracts were screened and relevant manuscripts were selected by the authors. Additional literature was obtained by searching references in the manuscripts. Relevant guidelines of the European League Against Rheumatism (EULAR), American College of Rheumatology (ACR) and British Society for Rheumatology (BSR) were included. A search in ClinicalTrials.gov was performed using the abovementioned search terms. Relevant trials were selected.

\section{Systemic lupus erythematosus}

SLE is a multisystem autoimmune disease with a high female predominance and heterogeneous clinical manifestations (constitutional, cutaneous, hematological, musculoskeletal, gastro-intestinal, neurological, renal, cardiorespiratory and serological) [8]. The disease is characterized by frequent flares and remissions. B-cells are central in the pathogenesis through the production of autoantibodies and cytokines [9].

Current treatment of mild-to-moderate SLE consists of antimalarials, low dose glucocorticoids, non-steroidal anti-inflammatory drugs (NSAIDs) and corticosteroidsparing agents such as methotrexate, azathioprine and mycophenolate mofetil. Moderate and severe disease activity is addressed with medium-to-high-dosed glucocorticoids, ciclosporin, belimumab or cyclophosphamide. Defined regimens including cyclophosphamide or mycophenolate mofetil are the first-line treatment for lupus nephritis [10-12].

The efficacy of rituximab has been explored in two randomized placebo-controlled trials (Table 1). In the EXPLORER trial, in which patients with extra-renal SLE activity were treated with rituximab or placebo on top of standard of care, no difference in major or partial clinical response was observed, except in the AfricanAmerican and Hispanic subgroup [13]. Rituximab did have a biological effect, with increased recuperation of complement levels and decreased anti-doublestranded DNA antibody titers. Post-hoc analysis of the data show that more rituximab-treated patients achieved low disease activity without major British Isles Lupus Assessment Group A (BILAG A) flares, suggesting a beneficial effect of rituximab [14]. It is argued that The EXPLORER trial was too stringent in the criteria for non-responders, allowing a relatively minor disease flare to be classified as non-response. The LUNAR trial, a randomized placebo-controlled trial evaluating the efficacy of rituximab on top of standard of care (mycophenolate mofetil and glucocorticoids) in patients with class III or IV lupus nephritis, did not meet its primary outcome and showed similar renal response rates at week 52 in both groups [15]. The exploratory endpoints did illustrate a trend to a reduction in proteinuria, improvement in renal function, a lower daily oral glucocorticoid dose and less need for rescue therapy with cyclophosphamide. Rituximab could therefore be considered an efficient glucocorticoid-sparing therapy. Several uncontrolled open-label studies and cohort studies (systematically reviewed in [16] and [17]), also show this glucocorticoid-sparing effect. Furthermore, these uncontrolled studies suggest efficacy of rituximab in patients with refractory SLE disease activity. When considering organ-specific refractory disease manifestations, rituximab seems effective in lupus nephritis, arthritis and immune thrombocytopenic purpura, with weaker evidence for an effect in autoimmune hemolytic anemia, cutaneous and neurological involvement.

ACR and EULAR guidelines state that rituximab can be used in lupus nephritis when conventional treatment with glucocorticoids and cyclophosphamide and/or mycophenolate mofetil have failed $[10,11]$. In non-renal moderate-to-severe SLE, rituximab can be considered in refractory cases, as mentioned in the guidelines of the British Society of Rheumatology [12].

\section{Systemic sclerosis}

SSc is a rare auto-immune disease characterized by progressive fibrosis of skin and internal organs, vascular alterations and immunological dysfunction [18]. Patients can be classified as limited (ISSc), limited cutaneous (IcSSc) or diffuse cutaneous (dcSSc) SSc, depending on the extent of the skin involvement. In this heterogeneous disease, not only the skin but also the gastro-intestinal, renal, cardiac, pulmonary and musculoskeletal system can be affected. The pathogenesis is

Table 1. Randomized controlled trials in systemic lupus erythematosus.

\begin{tabular}{|c|c|c|c|c|c|c|}
\hline Study & N & $\begin{array}{l}\text { RTX dose and } \\
\text { interval }\end{array}$ & Primary end point & Follow-up & SOC & $\begin{array}{l}\text { Primary end } \\
\text { point met? }\end{array}$ \\
\hline EXPLORER (extra-renal) [13] & $\begin{array}{l}257 \text { (169 RTX vs. } 88 \\
\text { placebo) }\end{array}$ & $\begin{array}{l}1 \mathrm{~g} \mathrm{IV} \\
\text { W 0-2 } \\
\text { W 24-26 }\end{array}$ & $\begin{array}{l}\text { Major or partial clinical } \\
\text { response }\end{array}$ & 52 weeks & AZA, MMF, MTX, GC & No \\
\hline LUNAR (nephritis) [15] & $\begin{array}{l}144 \text { (72 RTX vs. } 72 \\
\text { placebo) }\end{array}$ & $\begin{array}{l}1 \mathrm{~g} \mathrm{IV} \\
\text { W 0-2 } \\
\text { W } 24-26\end{array}$ & Renal response & 42 weeks & MMF, GC & No \\
\hline
\end{tabular}

RCT, randomized controlled trial; $N$, number of patients included; SOC, standard of care; IV, intravenously; W, week; RTX, rituximab; vs., versus; AZA azathioprine; MMF, mycophenolate mofetil; MTX, methotrexate; GC, glucocorticoids. 
incompletely understood, but emerging evidence points to the role of B cells, acting through secretion of cytokines, production of autoantibodies and direct B-cell contact with fibroblasts and dendritic cells [19].

Current treatment options for SSc are limited and are highlighted in the recently updated EULAR treatment recommendations. Methotrexate can be used as treatment for skin manifestations in early diffuse SSc. Mycophenolate mofetil and cyclophosphamide are recommended in progressive interstitial lung disease (ILD), the former being equally efficient and better tolerated [20]. In selected cases with rapid progressive disease, autologous hematopoietic stem cell transplantation could be considered [21].

The effect of rituximab has been evaluated in descriptive cohorts [22-24], two case-control studies $[25,26]$ and various interventional studies: several uncontrolled open-label studies [27-35], one randomized open-label trial [36] and one placebo-controlled randomized trial [37] (Supplemental Table 1). In these studies, considerable heterogeneity exists in the severity of skin and lung involvement, disease duration and concomitant treatment. The only randomized controlled trial comparing rituximab with placebo was underpowered, including only 8 patients per group, but showed a trend towards improvement in skin and lung involvement [37]. Overall, rituximab seems to stabilize and might improve skin involvement and lung function tests, when given on top of standard of care. Based on the available evidence, the BSR guidelines indicate possible use of rituximab in refractory skin disease [38]. Overall, one can consider the use of rituximab in early diffuse cutaneous SSc to stabilize or decrease skin fibrosis and attempt stabilization of lung volumes.

\section{Primary Sjögren syndrome}

pSS is the second most frequent autoimmune rheumatic disease after RA. The incidence is estimated to be 3-11/ 100.000 individuals per year [39]. The most common symptoms are oral and ocular dryness, pain and fatigue. Systemic involvement is present in 50-60\% [39]. Sjögren syndrome can be present on its own (primary SS) or in association with other connective-tissue diseases and is then referred to as secondary Sjögren syndrome and outside the scope of this article. According to the 'autoimmune epithelitis' theory, epithelial cells are in the center of the autoimmune response, in which B-cells play an important role [39]. Standard treatment for sicca symptoms includes local symptomatic treatment with tear substitution, oral moisturizers and pilocarpine. In systemic involvement glucocorticoids and hydroxychloroquine are often used [40,41].

Four RCTs have been published on the use of rituximab in the treatment of pSS, mostly focusing on sicca symptoms and fatigue (Table 2). The first two small studies met their primary end point whereas the last larger two did not. In the first trial Dass et al. noted a significant effect on the mean fatigue reduction compared to baseline after 6 months, but not on the proportions of patients achieving $20 \%$ reduction in fatigue from baseline [42]. In the second trial only changes in stimulated salivary flow at 12 weeks, and not at later time points, and ocular dryness at 36 and 48 weeks were significant [43]. The larger TEARS trial did not meet its primary end point ( $\geq 30 \mathrm{~mm}$ change in $\geq 2$ of 4 VAS) at 24 weeks but an early effect (weeks 6 to 16), particularly on fatigue, was noted [44]. To demonstrate a long-term effect, a second course of rituximab was administered at week 26 and 28 in the TRACTISS trial [45]. However, no early effect on fatigue (as in the TEARS trial) or late effect on ocular dryness (as reported by Meijer et al.) or other long-term effect was seen. Additionally, a cost-effectiveness analysis was negative. The baseline treatment in these trials differed: in the TRACTISS trial 55,6\% used hydroxychloroquine, whereas in the other trials use of other immunosuppressive agents outside of treatment intervention was not allowed.

A first criticism on both the TEARS and TRACTISS trials are the low baseline EULAR Sjögren Syndrome Disease Activity Index (ESSDAI) scores. A second point of critique was the choice of end points, though the ESSDAI, a secondary end point in the last two trials, should be able to detect a treatment effect of rituximab in RCTs, even at low mean ESSDAl scores [46].

Table 2. Randomized controlled trials in primary Sjögren syndrome.

\begin{tabular}{|c|c|c|c|c|c|c|}
\hline Study & $N$ & $\begin{array}{l}\text { RTX dose } \\
\text { and } \\
\text { interval }\end{array}$ & Primary end point & Follow-up & SOC & $\begin{array}{l}\text { Primary end point } \\
\text { met? }\end{array}$ \\
\hline Dass et al. [42] & $\begin{array}{l}17 \text { ( } 8 \text { RTX } \\
\text { vs. } 9 \\
\text { placebo) }\end{array}$ & $\begin{array}{l}1 \mathrm{~g} \mathrm{IV} \\
\text { W } 0-2\end{array}$ & Reduction of fatigue ( $>20 \%$ on VAS) & 6 months & Not further defined & $\begin{array}{c}\text { Yes }(\operatorname{RTX} p<0,001 \\
\text { vs. placebo } \\
p=0,147)\end{array}$ \\
\hline Meijer et al. [43] & $\begin{array}{l}30 \text { (20 RTX } \\
\text { vs. } 10 \\
\text { placebo) }\end{array}$ & $\begin{array}{l}1 \mathrm{~g} \mathrm{IV} \\
\text { W } 0-2\end{array}$ & $\begin{array}{l}\text { Improvement of stimulated salivary } \\
\text { flow rate }(\mathrm{ml} / \mathrm{min})\end{array}$ & 48 weeks & $\begin{array}{l}\text { Stop concomitant } \\
\text { medication before } \\
\text { baseline }\end{array}$ & Yes $(p=0,038)$ \\
\hline TEARS [44] & $\begin{array}{l}120(63 \text { RTX } \\
\text { vs. } 57 \\
\text { placebo) }\end{array}$ & $\begin{array}{l}1 \mathrm{~g} \mathrm{IV} \\
\text { W } 0-2\end{array}$ & $\begin{array}{l}\text { Significant effect ( } \geq 30 \mathrm{~mm} \text { ) on } \geq 2 \\
\text { VAS (fatigue, sicca symptoms, global } \\
\text { disease, pain) }\end{array}$ & 24 weeks & $\begin{array}{l}\text { Stop all immunosuppressive } \\
\text { medication } 4 \text { weeks } \\
\text { before baseline }\end{array}$ & No \\
\hline TRACTISS [45] & $\begin{array}{l}133(67 \text { RTX } \\
\text { vs. } 66 \\
\text { placebo) }\end{array}$ & $\begin{array}{l}1 \text { g IV } \\
\text { W } 0-2 \\
\text { W } 24-26\end{array}$ & $\begin{array}{l}\text { Significant effect on fatigue, oral } \\
\text { dryness (VAS) }\end{array}$ & 48 weeks & $\begin{array}{l}\text { Stable dose GC and } \\
\text { hydroxychloroquine }\end{array}$ & No \\
\hline
\end{tabular}

RCT, randomized controlled trial; N, number of patients included; SOC, standard of care; IV, intravenously; W, week; VAS, visual analog scale; RTX, rituximab; $\mathrm{ml}$, milliliter; GC, glucocorticoids. 
Prospective non-randomized trials (recently reviewed in [47]) with more active disease and systemic involvement show efficacy of rituximab. There was a significant effect of rituximab vs. DMARD treatment on ESSDAI scores in a prospective follow-up study of 41 early active pSS patients with a higher mean ESSDAI at baseline (20,3 in the rituximab group, 19,8 in the DMARD group) [48]. This study was characterized by frequent systemic involvement, a long follow-up period (120 months) and repeated use of rituximab. Another prospective registry study of 78 patients, of whom 74 had systemic involvement, demonstrated a good effect of rituximab according to the treating physician in $60 \%$ of patients. Articular, hematological, pulmonary, and renal involvement and vasculitis benefited most [49]. Rituximab shows some effect in peripheral neuropathy related to vasculitis and cryoglobulinemia but not in central neurological manifestations (such as multiple sclerosis-like symptoms) or peripheral non-vasculitis neuropathy [50,51].

According to the guidelines of the ACR, rituximab can be used for treatment of oral and ocular dryness after failure of conventional treatment although the strength of the recommendation was weak and the last and largest RCT, which was negative, had not yet been published $[45,52]$. As such, rituximab for sicca symptoms based on the current evidence remains highly debatable. The use of rituximab as a therapeutic option in systemic involvement is accepted and is recommended in the guidelines of the ACR and the British Society of Rheumatology [40,52].

\section{Idiopathic inflammatory myopathy}

The IIMs are a rare and heterogeneous group of diseases, including polymyositis (PM), dermatomyositis (DM), necrotizing autoimmune myositis, inclusion-body myositis and overlap myositis (overlapping with other CTDs). Muscle weakness is the central, though not-obligatory, feature. Skin features are typical of dermatomyositis, but skin involvement also occurs in other subtypes. Arthritis and ILD are frequently present, often as part of the antisynthetase syndrome (ASS). This syndrome is associated with antisynthetase antibodies (including anti-Jo-1, PL7, PL12, KS, OJ and EJ), the most prevalent myositis-specific antibodies (MSA). MSA-defined syndromes provide the base for a newly proposed clinico-serological classification [53]. The presence of autoantibodies in serum (up to $60 \%$ has MSAs) and T cells, macrophages, and dendritic cells in muscle tissue support involvement of immune mechanisms in the pathogenesis [54]. Glucocorticoids are the standard treatment, with immunosuppressive treatment as second-line therapy, though there is no highquality evidence supporting their use $[55,56]$.

The only randomized rituximab trial, the Rituximab in Myositis (RIM) trial, was negative. The primary end point was the time to achieve the International Myositis
Assessment and Clinical Studies Group preliminary definition of improvement (DOI), a composite of 6 core set measures [57]. This trial included refractory juvenile and adult PM and DM patients in a randomized placebophase study design. One arm received rituximab at weeks 0 and 1 and the other arm at weeks 8 and 9 . The slower-than-expected onset of action of rituximab in combination with a short 8-week placebo phase may explain the negative result. Though the primary end point was not met, $83 \%$ of all randomized patients met the DOI [57], a number in line with a response rate of $78.3 \%$ in a recent review which includes open label studies and case series [58]. The presence of autoantibodies, especially antisynthetase and anti-Mi-2 (another MSA), predicted clinical improvement at 20 weeks. The clinico-pathological subtype (PM and DM) and age group (juvenile vs. adult) did not [59].

Skin and pulmonary involvement seem to benefit from rituximab. An analysis of skin rashes of DM patients in the RIM trial showed a significant effect on a cutaneous visual analog scale. Classical DM signs, the heliotrope rash and Gottron papules; and erythematous rashes without ulceration or necrosis improved most [60]. Rituximab shows promise in IIM-associated ILD. In a retrospective analysis of the RIM trial, improvement of pulmonary function testing, was noted in 6 of 8 patients with ILD [61]. In a case series of 7 anti-Jo-1 patients with ILD treated with rituximab in combination with glucocorticoids only, after 1 year the pulmonary symptoms, pulmonary function tests (forced vital capacity (FVC) and diffusion capacity for carbon monoxide (DLCO)) and highresolution computed tomography were significantly better [62]. In detail, the median level of FVC increased from $66 \%$ to $74 \%(p=0,04)$ and the median level of DLCO increased from $39 \%$ to $59 \%(p=0,001)$.

No guidelines on treatment of IIM by the ACR, EULAR or BSR have been published, but there is a consensus for use of rituximab in refractory myositis. Autoantibody status is the most useful predictor of treatment success with rituximab for now. The use of rituximab in IIM-associated ILD will be explored, together with other CTD-ILD, in the RECITAL trial [63].

\section{Practical use and safety}

Rituximab can be administered intravenously (IV) or subcutaneously. In autoimmune disease, only IV administration has been studied. The most widely used course (the 'RA dose') consists of $1000 \mathrm{mg}$ at week 0 and 1 or $2[13,15,26,37,44,45,57]$. The number of courses, one or more, depends on the indication (Table 3). The premedication consists of paracetamol (1 g), an antihistaminic (e.g. diphenhydramine) and the equivalent of $100 \mathrm{mg}$ methylprednisolone. During the first infusion, the initial infusion rate is $50 \mathrm{mg} /$ hour and can be increased by $50 \mathrm{mg} / \mathrm{hour}$ 
Table 3. Indications for rituximab in systemic autoimmune rheumatic disease.

\begin{tabular}{lllll}
\hline SARD & \multicolumn{1}{c}{ Indication } & Combination therapy? & Single course or to be repeated? & $\begin{array}{c}\text { Guidelines endorsement } \\
\text { (LOE, SOR) }\end{array}$ \\
\hline SLE & Refractory moderate-to-severe SLE & On top of SOC & To be repeated & BSR (2+, C) [12] ACR (C) \\
SSC & Refractory skin involvement & On top of SOC & To be repeated & BSR (III, C) [38] \\
& SSc-associated ILD & On top of SOC & To be repeated & No formal recommendation \\
pSS & Systemic involvement & On top of SOC & To be repeated & ACR (Moderate) [52] \\
& & On top of GC & Single course (IIb, B) [40] & No guidelines available \\
IIM & Refractory myositis & On &
\end{tabular}

SARD, systemic autoimmune rheumatic disease; LOE, level of evidence; SOR, strength of recommendation; SLE, systemic lupus erythematosus; SSC, systemic sclerosis; pSS, primary Sjögren syndrome; IIM, idiopathic inflammatory myopathy; ILD, interstitial lung disease; SOC, standard of care; GC, glucocorticoids; BSR, British Society of Rheumatology; ACR, American College of Rheumatology.

every $30 \mathrm{~min}$ to a maximal infusion rate of $400 \mathrm{mg} /$ hour. In RA, a faster infusion rate can be used if the first infusion is well tolerated. The initial infusion rate in this accelerated scheme is $250 \mathrm{mg} /$ hour during the first $30 \mathrm{~min}$ and $600 \mathrm{mg} /$ hour during the next 90 min which translates to a total infusion time of approximately $2 \mathrm{~h}$ [64].

Infusion-related reactions (IRRs) are common, especially when no premedication is given, and may be related to release of cytokines. IRRs include hypertension and hypotension, nausea, rash, pyrexia, urticaria and in more severe cases generalized edema or angioedema, bronchospasm and anaphylaxis. The overall incidence of IRR in RA trials was $36 \%$ but $<1 \%$ was serious. IRRs occurred most frequently during the first infusion. The number of IRRs in the previously discussed RCTs varied between 1 and 16,4\% [13,15,44,45,57]. In case of an IRR rituximab should be stopped and supportive care provided. If the IRR is not severe and symptoms resolve completely, rituximab can be resumed at a slower infusion rate ( $50 \%$ reduction).

Infections are the most prevalent side effect next to IRRs. In the RA trials, overall infection rate was 94 per 100 patient years of which only 4 (out of 94) were serious or required intravenous antibiotics. Respiratory and urinary tract infections occurred most often. In the previously mentioned RCTs, in which combination therapy with DMARD was frequent, a serious infectious adverse event was noted in $3-19.2 \%[13,26,45,57]$. Cases of progressive multifocal leukoencephalopathy in treatment of autoimmune diseases with rituximab have been reported $[65,66]$. Hypogammaglobulinemia has been observed but is not associated with an increased infection risk in $\mathrm{RA}$, in contrast to rituximab use in hematological malignancies [67]. Mild-to-moderate neutropenia occurs, but severe neutropenia is rare.

Before the start of rituximab, a screening for latent infections (tuberculosis, hepatitis B and C, HIV) and review of the vaccination status should be performed. Yearly vaccination against seasonal flu and pneumococcal vaccination (the 13-valent conjugated vaccine PCV13, followed after at least 8 weeks by the 23-valent non-conjugated vaccine PPV23, this latter being repeated every 5 years) are recommended. Vaccines should be given 4 weeks before the start or at least 6 months after the last administration of rituximab, because of potential reduced response rate. Live viral vaccines (e.g. yellow fever, herpes zoster) can only be administered at least 4 weeks before the start of rituximab. There are currently no data available to support a recommendation on the minimal interval between the stop of rituximab and the administration of live vaccines. According to the half-life of rituximab and the studies about immunogenicity of inactivated vaccines $[68,69]$, it could be safe at least 12 months after the last rituximab administration, if immunoglobulin levels and CD 19 + B-cells are normal. However, until more data are available, the use of live vaccines is contraindicated

Table 4. Upcoming phase-2 and -3 trials of rituximab in systemic autoimmune rheumatic disease.

\begin{tabular}{|c|c|c|c|c|c|}
\hline Trial & Phase & Indication & $\begin{array}{l}\text { Intervention + comparison if } \\
\text { applicable }\end{array}$ & Primary outcome measure (time) & Status \\
\hline RECITAL [63] & $2 / 3$ & CTD-ILD & RTX vs. CYC & Absolute change in FVC (W 48) & Recruiting \\
\hline BLISS-BELIEVE [72] & 3 & SLE & $\begin{array}{l}\text { BEL + RTX + SOC } \\
\text { vs. BEL + placebo + SOC } \\
\text { vs. BEL + SOC }\end{array}$ & Disease control (W 52) & $\begin{array}{l}\text { Not yet } \\
\text { recruiting }\end{array}$ \\
\hline ROOTS [73] & 2 & $\begin{array}{l}\text { SLE: skin disease, } \\
\text { arthritis }\end{array}$ & RTX + CS vs. CS & Feasibility of trial (W 24) & Recruiting \\
\hline RITUXILUP [74] & 3 & Lupus nephritis & $\begin{array}{l}\text { RTX + CS + MMF } \\
\text { vs. CS + MMF }\end{array}$ & $\begin{array}{l}\text { Complete renal response without need of PO } \\
\text { CS (W 52) }\end{array}$ & Terminated \\
\hline SYNBloSe [75] & 2 & Lupus nephritis & $\mathrm{BEL}+\mathrm{RTX}$ & Reduction of pathogenic autoantibodies (W 24) & Enrolling \\
\hline RECOVER [76] & $2 / 3$ & $\begin{array}{l}\text { SSc: articular } \\
\text { symptoms }\end{array}$ & RTX vs. placebo & $\begin{array}{l}\text { Number of tender and swollen joints out of } 53 \\
\text { joints (W 26) }\end{array}$ & Completed \\
\hline NC02631538 [77] & 2 & pSS & $\begin{array}{l}\text { BEL + RTX } \\
\text { vs. BEL vs. RTX } \\
\text { vs. placebo }\end{array}$ & Number of SAEs and AESIs (W 104) & Recruiting \\
\hline EvER-ILD [78] & 3 & ILD, NSIP pattern & RTX + MMF vs. MMF & Change in FVC (W 24) & Recruiting \\
\hline
\end{tabular}

CTD, connective tissue disease; ILD, interstitial lung disease; RTX, rituximab; CYC, cyclophosphamide; FVC, forced vital capacity; W, week; SLE, systemic lupus erythematosus; BEL, belimumab; CS, corticosteroids; PO, peroral; MMF, myophenolate mofetil; SSc, systemic sclerosis; SAE, severe adverse event; AESI, adverse events of special interest; NSIP, non-specific interstitial pneumonia; vs., versus. 
once rituximab is started [70]. Pregnancy and breastfeeding is not recommended up to 12 months after the last administration of rituximab, although unintentional rituximab exposure early in the first trimester is unlikely to be harmful [71]. At present, there are no recommendations on the use of rituximab in patients with a history of or active malignancy. Rituximab is contraindicated in active, severe infections, severely immunocompromised patients and patients with severe heart failure or other uncontrolled cardiac disease [64].

\section{Conclusion}

Rituximab is a treatment option in several SARDs (Table 3). Current evidence supports use of rituximab in refractory moderate-to-severe SLE, SSc with refractory skin involvement, and pSS with systemic involvement. There is a consensus for use in refractory myositis. The role of rituximab in ILD will be further explored in the RECITAL and EvER-ILD trial. Several other trials of rituximab in SARD are upcoming or ongoing (Table 4). Rituximab has a good safety profile, but the treating physician should be aware of possible infusion reactions and their appropriate treatment, as well of the increased risk of infection.

\section{Disclosure statement}

No potential conflict of interest was reported by the authors.

\section{ORCID}

Nathalie Berghen (D) http://orcid.org/0000-0002-4129-6341 Jean-Baptiste Vulsteke (D) http://orcid.org/0000-0001-57532794

\section{References}

[1] Kuijpers TW, Bende RJ, Baars PA, et al. CD20 deficiency in humans results in impaired T cell-independent antibody responses. J Clin Invest. 2010;120 (1):214-222.

[2] Weiner GJ. Rituximab: mechanism of action. Semin Hematol. 2010;47(2):115-123.

[3] Harrison AM, Thalji NM, Greenberg AJ, et al. Rituximab for Non-Hodgkin's Lymphoma: a story of rapid success in translation. Clin Transl Sci. 2014;7 (1):82-86.

[4] Stone PA, Spiera R, Seo P, et al. RAVE-ITN Research Group. SR. S. Rituximab versus cyclophosphamide for ANCA-associated vasculitis. N Engl J Med. 2010;363 (3):221-232.

[5] Guillevin L, Pagnoux C, Karras A, et al. Rituximab versus azathioprine for maintenance in ANCA-associated vasculitis. N Engl J Med. 2014;371(19):17711780.

[6] Smolen JS, Landewe R, Bijlsma J, et al. EULAR recommendations for the management of rheumatoid arthritis with synthetic and biological disease-modifying antirheumatic drugs: 2016 update. Ann Rheum Dis. 2017;76(6):960-977.

[7] IV§8940000, Koninklijk Besluit van 21 december 2001 tot vaststelling van de procedures, termijnen en voorwaarden inzake de tegemoetkoming van de verplichte verzekering voor geneeskundige verzorging en uitkeringen in de kosten van farmaceutische specialiteiten.

[8] Rahman DAAI. Systemic lupus erythematosus. N Engl J Med. 2008;28(358):9.

[9] Dorner T, Lipsky PE. Beyond pan-B-cell-directed therapy - new avenues and insights into the pathogenesis of SLE. Nat Rev Rheumatol. 2016;12(11):645-657.

[10] Hahn BH, McMahon MA, Wilkinson A, et al. American College of Rheumatology guidelines for screening, treatment, and management of lupus nephritis. Arthritis Care Res. 2012;64(6):797-808.

[11] Bertsias GK, Tektonidou M, Amoura Z, et al. Joint European League Against Rheumatism and European Renal Association-European Dialysis and Transplant Association (EULAR/ERA-EDTA) recommendations for the management of adult and paediatric lupus nephritis. Ann Rheum Dis. 2012;71(11):1771-1782.

[12] Gordon C, Gayed M, Brown S, et al. British Society for Rheumatology guideline for the management of systemic lupus erythematosus in adults. Rheumatol. 2017;epub(6 October): 1-45. Suppl.

[13] Merrill JT, Neuwelt CM, Wallace DJ, et al. Efficacy and safety of rituximab in moderately-to-severely active systemic lupus erythematosus: the randomized, double-blind, phase II/III systemic lupus erythematosus evaluation of rituximab trial. Arthritis Rheum. 2010;62(1):222-233.

[14] Merrill J, Furie R, Latinis K, et al. Assessment of flares in lupus patients enrolled in a phase II/III study of rituximab (EXPLORER). Lupus. 2011;20(7):709-716.

[15] Rovin BH, Furie R, Latinis K, et al. Efficacy and safety of rituximab in patients with active proliferative lupus nephritis: the Lupus Nephritis Assessment with Rituximab study. Arthritis Rheum. 2012;64(4):1215-1226.

[16] Duxbury B, Combescure C, Chizzolini C. Rituximab in systemic lupus erythematosus: an updated systematic review and meta-analysis. Lupus. SAGE Publications Ltd STM. 2013 Oct 17;22(14):1489-1503.

[17] Cobo-lbanez T, Loza-Santamaria E, Pego-Reigosa JM, et al. Efficacy and safety of rituximab in the treatment of non-renal systemic lupus erythematosus: a systematic review. Semin Arthritis Rheum. 2014;44 (2):175-185.

[18] Gabrielli EV, Krieg TAA. Scleroderma. N Engl J Med. 2009;360(19):1989-2003.

[19] Sakkas LI, Bogdanos DP. Systemic sclerosis: new evidence re-enforces the role of $B$ cells. Autoimmun Rev. 2016;15(2):155-161.

[20] Tashkin DP, Roth MD, Clements PJ, et al. Mycophenolate mofetil versus oral cyclophosphamide in scleroderma-related interstitial lung disease (SLS II): a randomised controlled, double-blind, parallel group trial. Lancet Respir Med. 2016;4(9):708-719.

[21] Kowal-Bielecka O, Fransen J, Avouac J, et al. Update of EULAR recommendations for the treatment of systemic sclerosis. Ann Rheum Dis. 2017;76(8):13271339.

[22] Giuggioli D, Lumetti F, Colaci $M$, et al. Rituximab in the treatment of patients with systemic sclerosis. Our experience and review of the literature. Autoimmun Rev. 2015;14(11):1072-1078. 
[23] Vilela VS, Maretti GB, Gama LM, et al. Rituximab for the therapy of systemic sclerosis: a series of 10 cases in a single center. Rev Bras Reum Engl Ed. 2016;56 (5):458-463.

[24] Lepri J, Airò P, Anguita Santos F, et al. Effects of rituximab in connective tissue disorders related interstitial lungdisease. Clin Exp Rheumatol. 2016;34 Suppl 1(5):181-185.

[25] Thiebaut M, Launay D, Riviere S, et al. Efficacy and safety of rituximab in systemic sclerosis: French retrospective study and literature review. Autoimmun Rev. 2018;17(6):582-587.

[26] Jordan S, Distler JHW, Maurer B, et al. Effects and safety of rituximab in systemic sclerosis: an analysis from the European Scleroderma Trial and Research (EUSTAR) group. Ann Rheum Dis. 2015;74(6):1188-1194.

[27] Smith V, Van Praet JT, Vandooren B, et al. Rituximab in diffuse cutaneous systemic sclerosis: an open-label clinical and histopathological study. Ann Rheum Dis. 2010;69(1):193-197.

[28] Smith V, Piette Y, van Praet JT, et al. Two-year results of an open pilot study of a 2-treatment course with rituximab in patients with early systemic sclerosis with diffuse skin involvement. J Rheumatol. 2013;40(1):52-57.

[29] Melsens K, Vandecasteele E, Deschepper E, et al. Two years follow-up of an open-label pilot study of treatment with rituximab in patients with early diffuse cutaneous systemic sclerosis. Acta Clin Belg. 2018;73(2):119-125.

[30] Daoussis SN, Tsamandas AC, Kalogeropoulou C, et al. Effect of long-term treatment with rituximab on pulmonary function and skin fibrosis in patients with diffuse systemic sclerosis. Clin Exp Rheumatol. 2012;30(2 Suppl 71):S17-22.

[31] Daoussis D, Melissaropoulos K, Sakellaropoulos G, et al. A multicenter, open-label, comparative study of B-cell depletion therapy with Rituximab for systemic sclerosis-associated interstitial lung disease. Semin Arthritis Rheum. 2017;46(5):625-631.

[32] Moazedi-Fuerst SM, Brickmann K, Hermann J, et al. Rituximab for systemic sclerosis: arrest of pulmonary disease progression in five cases. Results of a lower dosage and shorter interval regimen. Scand J Rheumatol. 2014;43(3):257-258.

[33] Bosello S, De Santis M, Lama G, et al. B cell depletion in diffuse progressive systemic sclerosis: safety, skin score modification and IL- 6 modulation in an up to thirty-six months follow-up open-label trial. Arthritis Res Ther. 2010;12(2):R54.

[34] Bosello SL, De Luca G, Rucco $M$, et al. Long-term efficacy of $B$ cell depletion therapy on lung and skin involvement in diffuse systemic sclerosis. Semin Arthritis Rheum. 2015;44(4):428-436.

[35] Lafyatis R, Kissin E, York M, et al. B cell depletion with rituximab in patients with diffuse cutaneous systemic sclerosis. Arthritis Rheum. 2009;60(2):578-583.

[36] Daoussis D, Liossis SN, Tsamandas AC, et al. Experience with rituximab in scleroderma: results from a 1-year, proof-of-principle study. Rheumatol. 2010;49(2):271-280.

[37] Boonstra $M$, Meijs J, Dorjée $A L$, et al. Rituximab in early systemic sclerosis. RMD Open. 2017;3:2.

[38] Denton CP, Hughes M, Gak N, et al. BSR and BHPR guideline for the treatment of systemic sclerosis. Rheumatology. 2016;55(10):1906-1910.

[39] Brito-Zeron P, Baldini C, Bootsma $H$, et al. Sjogren syndrome. Nat Rev Dis Prim. 2016;2:16047.
[40] Price EJ, Rauz S, Tappuni AR, et al. The British Society for Rheumatology guideline for the management of adults with primary Sjögren's Syndrome. Rheumatology. 2017; March:24-48.

[41] Mariette $X$, Criswell LA. Primary Sjögren's Syndrome. N Engl J Med. 2018;378(10):931-939.

[42] Dass S, Bowman SJ, Vital EM, et al. Reduction of fatigue in Sjögren syndrome with rituximab: results of a randomised, double-blind, placebo-controlled pilot study. Ann Rheum Dis. 2008;67(11):1541-1544.

[43] Meijer JM, Meiners PM, Vissink A, et al. Effectiveness of rituximab treatment in primary Sjogren's syndrome: a randomized, double-blind, placebo-controlled trial. Arthritis Rheum. 2010;62(4):960-968.

[44] Devauchelle-Pensec V, Mariette X, Jousse-Joulin S, et al. Treatment of Primary Sjögren Syndrome With Rituximab. Ann Intern Med. 2014;160(4):233-242.

[45] Bowman SJ, Everett CC, O'Dwyer JL, et al. Randomized Controlled Trial of Rituximab and CostEffectiveness Analysis in Treating Fatigue and Oral Dryness in Primary Sjögren's Syndrome. Arthritis Rheumatol. 2017;69(7):1440-1450.

[46] R V M, Arends S, Meiners PM, et al. EULAR Sjögren's Syndrome Disease Activity Index (ESSDAl) is sensitive to show efficacy of rituximab treatment in a randomised controlled trial. Ann Rheum Dis. 2014;73(2):472-474.

[47] Verstappen GM, Nimwegen Van JF, Vissink A, et al. The value of rituximab treatment in primary Sjögren ' s syndrome. Clin Immunol. 2017;182:62-71.

[48] Carubbi F, Cipriani P, Marrelli A, et al. Efficacy and safety of rituximab treatment in early primary Sjogren's syndrome: a prospective, multi-center, follow-up study. Arthritis Res Ther. 2013;15(5):R172-R172.

[49] Gottenberg JE, Cinquetti G, Larroche C, et al. Efficacy of rituximab in systemic manifestations of primary Sjögren's syndrome: results in 78 patients of the Autolmmune and Rituximab registry. Ann Rheum Dis. 2013;72(6):1026-1031.

[50] Mekinian A, Ravaud P, Hatron PY, et al. Efficacy of rituximab in primary Sjögren's syndrome with peripheral nervous system involvement: results from the AIR registry. Ann Rheum Dis. 2012;71(1):84-87.

[51] Mekinian A, Ravaud P, Larroche C, et al. Rituximab in central nervous system manifestations of patients with primary Sjogren's syndrome: results from the AIR registry. Clin Exp Rheumatol. 2012;30(2):208-212.

[52] Carsons SE, Vivino FB, Parke A, et al. Treatment Guidelines for Rheumatologic Manifestations of Sjögren's Syndrome: use of Biologic Agents, Management of Fatigue, and Inflammatory Musculoskeletal Pain. Arthritis Care Res. 2017;69(4):517-527.

[53] Senécal JL, Raynauld JP, Troyanov Y. Editorial: a New Classification of Adult Autoimmune Myositis. Arthritis Rheumatol. 2017;69(5):878-884.

[54] Venalis P, Lundberg IE. Immune mechanisms in polymyositis and dermatomyositis and potential targets for therapy. Rheumatology. 2014;397-405.

[55] Dalakas MC. Inflammatory Muscle Diseases. Longo DL, editor. N Engl J Med. 2015 Apr;372(18):1734-1747.

[56] Gordon PA, Winer JB, Hoogendijk JE, et al. Immunosuppressant and immunomodulatory treatment for dermatomyositis and polymyositis. Cochrane Database of Systematic Reviews. 2012;(8).

[57] Oddis CV, Reed AM, Aggarwal R, et al. Rituximab in the treatment of refractory adult and juvenile dermatomyositis and adult polymyositis: a randomized, placebo-phase trial. Arthritis Rheum. 2013;65(2):314-324. 
[58] Fasano S, Gordon P, Hajji R, et al. Rituximab in the treatment of inflammatory myopathies: a review. Rheumatology. 2017;56(1):26-36.

[59] Aggarwal R, Bandos A, Reed AM, et al. Predictors of clinical improvement in rituximab-treated refractory adult and juvenile Dermatomyositis and adult polymyositis. Arthritis Rheumatol. 2014;66(3):740-749.

[60] Aggarwal R, Loganathan P, Koontz D, et al. Cutaneous improvement in refractory adult and juvenile dermatomyositis after treatment with rituximab. Rheumatol. 2017;56(2):247-254.

[61] Unger L, Kampf S, Lüthke K, et al. Rituximab therapy in patients with refractory dermatomyositis or polymyositis: differential effects in a real-life population. Rheumatol. 2014;53(9):1630-1638.

[62] Marie I, Dominique $S$, Janvresse A, et al. Rituximab therapy for refractory interstitial lung disease related to antisynthetase syndrome. Respir Med. 2012;106(4):581-587.

[63] ClinicalTrials.gov [Internet]. Bethesda (MD): National Library of Medicine, (US). Rituximab Versus Cyclophosphamide in Connective Tissue Disease-ILD. 2013. [cited 2018 Feb 18]. Available from: https:// clinicaltrials.gov/ct2/show/NCT01862926

[64] AG RP. Mabthera: summary of Product Characteristics. European Medicines Agency. 2016. p. 180. Available from: http://www.ema.europa.eu/ema/index.jsp?curl= pages/medicines/human/medicines/000165/human_ med_000897.jsp\&murl=menus/medicines/medicines. jsp\&mid=WC0b01ac058001d124. Accessed on 2018 Feb 18.

[65] Clifford DB, Ances B, Costello C, et al. Rituximab-associated progressive multifocal leukoencephalopathy in rheumatoid arthritis. Arch Neurol. 2011;68(9):1156-1164.

[66] Marie I, Guegan-Massardier E, Levesque H. Progressive multifocal leukoencephalopathy in refractory polymyositis treated with rituximab. Eur J Intern Med. 2011;22(3): e13-4.

[67] Casulo C, Maragulia J, Zelenetz AD. Incidence of hypogammaglobulinemia in patients receiving rituximab and the use of intravenous immunoglobulin for recurrent infections. Clin Lymphoma, Myeloma Leuk. 2013;13(2):106-111.

[68] Assen Van S, Holvast A, Benne CA, et al. Humoral Responses After Influenza Vaccination Are Severely Reduced in Patients With Rheumatoid Arthritis Treated With Rituximab. Arthritis Rheum. 2010;62 (1):75-81.

[69] Bühler S, Eperon G, Ribi C, et al. Vaccination recommendations for adult patients with autoimmune inflammatory rheumatic diseases. Swiss Med Wkly. 2015 Jul 28;145:w14159.

[70] Assen Van S, Elkayam O, Cervera R, et al. EULAR recommendations for vaccination in adult patients with autoimmune inflammatory rheumatic diseases. Ann Rheum Dis. 2011 Mar;70(3):414-422.

[71] Flint J, Panchal S, Hurrell A, et al. Guidelines BSR and BHPR guideline on prescribing drugs in pregnancy and breastfeeding - part I : standard and biologic disease modifying anti-rheumatic drugs and corticosteroids. Rheumatology. 2016 Sep;55(9):1693-1697.

[72] ClinicalTrials.gov [Internet]. Bethesda (MD): National Library of Medicine. A Study to Evaluate the Efficacy and Safety of Belimumab Administered in Combination With Rituximab to Adult Subjects With Systemic Lupus Erythematosus (SLE) - BLISSBELIEVE. 2017. [cited 2018 Feb 18]. Available from: https://clinicaltrials.gov/ct2/show/NCT03312907

[73] ClinicalTrials.gov [Internet]. Bethesda (MD): National Library of Medicine. Rituximab Objective Outcome Measures Trial in SLE (ROOTS). 2017. [cited 2018 Feb 18]. Available from: https://clinicaltrials.gov/ct2/show/ NCT03054259

[74] ClinicalTrials.gov [Internet]. Bethesda (MD): National Library of Medicine. Trial of Rituximab and Mycophenolate Mofetil Without Oral Steroids for Lupus Nephritis (RITUXILUP). 2013. [cited 2018 Feb 18]. Available from: https://clinicaltrials.gov/ct2/ show/NCT01773616

[75] ClinicalTrials.gov [Internet]. Bethesda (MD): National Library of Medicine. Synergetic B-cell Immodulation in SLE (SYNBloSe). [cited 2018 Feb 18]. Available from: https://clinicaltrials.gov/ct2/show/NCT02284984

[76] ClinicalTrials.gov [Internet]. Bethesda (MD): National Library of Medicine. Rituximab in Systemic Sclerosis (RECOVER). 2012. [cited 2018 Feb 18]. Available from: https://www.clinicaltrials.gov/ct2/show/NCT01748084

[77] ClinicalTrials.gov [Internet]. Bethesda (MD): National Library of Medicine. Safety and Efficacy Study of Subcutaneous Belimumab and Intravenous Rituximab Co-administration in Subjects With Primary Sjogren's Syndrome. 2015. [cited 2018 Feb 18]. Available from: https://www.clinicaltrials.gov/ct2/show/NCT02631538

[78] ClinicalTrials.gov [Internet]. Bethesda (MD): National Library of Medicine. Evaluation of Efficacy and Safety of Rituximab With Mycophenolate Mofetil in Patients With Interstitial Lung Diseases (EvER-ILD). [cited 2018 Feb 18]. Available from: https://clinicaltrials.gov/ct2/ show/NCT02990286 